\title{
Primary idiopathic osteolysis: description of a family
}

\author{
Antonio Naranjo, Miguel A Muniain, Javier Martín, José Vázquez, José Núñez
}

\begin{abstract}
A clinical, analytical, and radiological study was carried out on three members of the same family with multicentric idiopathic osteolysis. Transmission appeared to be via the dominant autosome present in the mother and two daughters. In the daughters osteolysis was seen in the carpal and tarsal bones, whereas in the mother radiology showed it to be in the phalanges of the hands and feet.
\end{abstract}

(Ann Rheum Dis 1992; 51: 1074-1078)

Primary idiopathic osteolysis is rare. It is characterised by the spontaneous onset of bone resorption and there are no known causative factors. Bone which previously appeared normal undegoes partial or complete resorption. The process continues for several years then stops spontaneously. ${ }^{1}$ The results of this destructive phenomenon are severe deformities and serious functional disabilities. The pathogenetic mechanism of the osteolysis is not known. Malignant nephropathies can occur in some forms of the disease.

Most workers agree that the first case of this syndrome was reported by Froelich ${ }^{2}$ who described an 18 year old girl with carpotarsal osteolysis which had begun when she was two years old. In 1976 Tyler and Rosenbaum used the term multicentric idiopathic osteolysis to describe a rare disease usually occurring in the carpotarsal area which was associated with severe and extensive osteolysis and had previously been described under a variety of names. These included idiopathic osteolysis, essential osteolysis, progressive essential osteolysis, essential acro-osteolysis, familial osteolysis, hereditary osteolysis, carpotarsal agenesis, familial carpal dysostosis, and bilateral carpal necrosis.

Torg and Steel ${ }^{4}$ classified osteolysis into four types: multicentric idiopathic osteolysis with dominant transmission, multicentric idiopathic osteolysis with recessive transmission, nonhereditary multicentric idiopathic osteolysis with nephropathy, and Gorham's massive osteolysis. MacPherson et $a^{5}$ added a fifth type: Winchester's syndrome.

In this paper we report the case of a family with primary idiopathic osteolysis and review previously published cases.

Case reports

PATIENT NO 1

This 18 year old woman has deformity in the flexion of the fifth fingers of both hands. Her delivery and subsequent development were normal with no history of trauma. Her symptoms began with pain, slight swelling, and limitation of movement in her wrists at the age of 5 years, accentuated by slight traumas. She had occasional pain in her elbows, right shoulder, dorsal spine, left knee, and dorsum of the left foot, with slight swelling in the left knee and foot. There were no constitutional symptoms, but she was depressive from 14 years of age.

On physical examination her blood pressure was $110 / 70 \mathrm{mmHg}$, her weight $45 \mathrm{~kg}$, and height $155 \mathrm{~cm}$. She was in good general health but was of low intelligence. Her gait was normal and her cervical spine slightly painful in left lateral flexion but with normal mobility. There was right convexity scoliosis of the dorsal rachis. Her wrists had a painful flexoextension limitation at $20^{\circ}$ and decreased bilateral strength. The left ankle and midfoot were painful in planar flexion. There was pain when pressure was applied to the metatarsophalangeal joints of the left foot. She had also bilateral hallux valgus and feet cava (grade II) with claw feet.

Her differential blood count, globular sedimentation rate, and blood and urine chemistry (creatinine, calcium, phosphorus, alkaline phosphatase, IgM rheumatoid factor, antinuclear antibodies, and mucopolysaccharides in urine) were normal.

Radiological examination showed deformity in the flexion of both fifth fingers and carpal osteolysis and hypoplasia of the tufts of the distal phalanges (fig 1). Figure 2 shows the morphology of cava feet; the left foot was the most affected and was $1 \mathrm{~cm}$ shorter and narrower than the right. Osteolysis was present in the tufts of the bilateral distal phalanges and the tubular diameter of the left foot metatarsals was decreased. Dorsal scoliosis and right convexity of the rachis was seen. Spina bifida was classified as S1. There was slight insufficiency in the bilateral cotyloid cavity of the hips. No pathological features were noted in plain radiographs of the thorax, skull, knees, or elbows. No pathological study was performed.

The patient remains asymptomatic with a moderate decrease in hand strength; in spite of this her functional capacity is good. She has orthoses for her feet.

\section{PATIENT NO 2}

This 4 year old girl, the sister of patient No 1 , had a normal delivery and began walking at 12 months. At 18 months she had a slight electric shock to the left hand. From 2 years of age she 


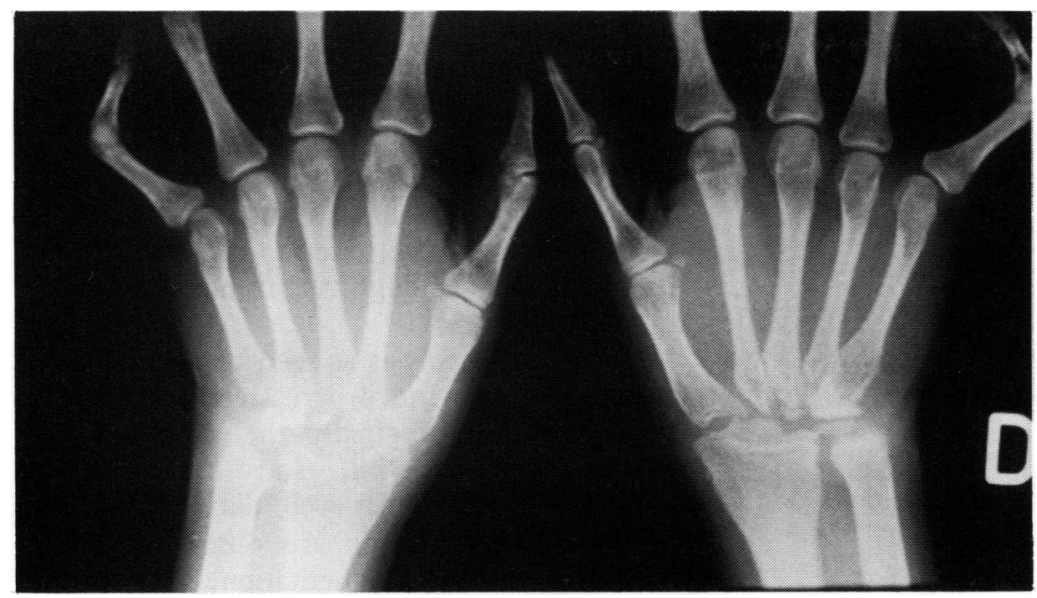

Figure 1 Hand radiographs of patient No 1 (aged 18 years) showing diffuse osteoporosis. Both carpus joints have disappeared. Sharpening of the base of the metacarpal joints can be seen.

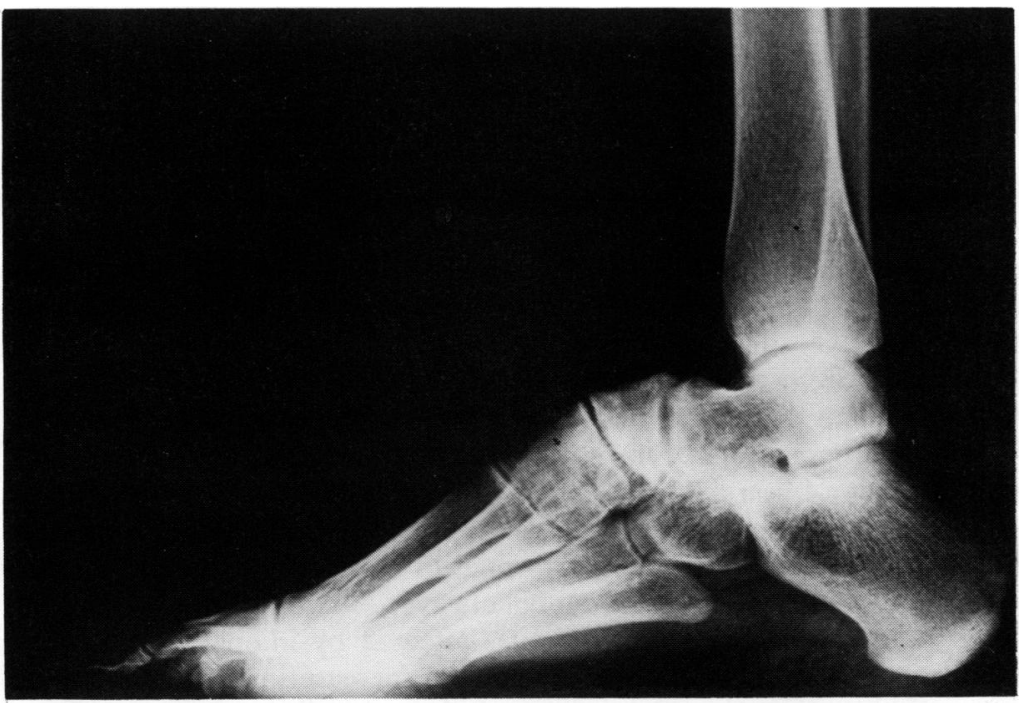

Figure 2 Radiographs for patient No 2 showing cava foot. A decrease is seen in the size of the astragalus, scaphoids, and cuneiforms, with irregularities and sclerosis in the articular spaces, though these were preserved.

Figure 3 Radiograph of the left hand of patient No 2 showing sclerosis and had pain in her left wrist and ankle without swelling accompanied by slight functional impairment. Her mother reported a decrease in the size of her left leg and foot.

On physical examination her blood pressure was $95 / 60 \mathrm{mmHg}$, her weight $26 \mathrm{~kg}$, and height $104 \mathrm{~cm}$. She was in good general health and her intelligence and hearing were normal. There was slight lameness of her left foot. Her left wrist was painful with limited flexoextension and her left leg and foot hypotrophied compared with the right and were painful on movement of the ankle and midfoot. Laboratory investigations were normal.

Radiological examination showed normal bone age. Initial osteolysis of the left carpus was seen (fig 3). There was osteoporosis of her left foot with sclerosis and a decrease in size of the scaphoids and narrowing of the midfoot articular spaces. Her right foot was normal. Plain radiographs of her skull, rachis, thorax, hips, and knees were normal.

The patient remains stable with slight arthralgias in the left wrist and foot. Treatment consists of aspirin and wrist ferules.

\section{PATIENT NO 3}

This patient is the 40 year old mother of patients 1 and 2. There are no antecedents of consanguinity. The patient has reported flexion deformities of her fingers without pain since adolescence and pain in the soles of her feet for the past 15 years. For the last five years she has had arthralgias in the proximal interphalanges of her hands.

On physical examination her blood pressure was $105 / 75 \mathrm{mmHg}$, her weight $56 \mathrm{~kg}$ and height $155 \mathrm{~cm}$. She was in good general health. Deformities on flexion of the proximal interphalanges of the fourth and fifth right and second and third left fingers were seen. She had feet cava (grade II) with subcutaneous fibrosis in the first right metatarsal joint.

A complete series of laboratory tests was carried out as in cases 1 and 2 . The results were normal or negative.

Radiological examination showed osteolysis in the tufts of the distal phalanges of her hands with sharpening of the epiphysis in some middle phalanges. Her feet showed osteolysis in the tufts of the distal phalanges and to a lesser extent in the proximal joints. Plain radiographs of the skull, rachis, thorax, and pelvis were normal.

\section{OTHER FAMILY MEMBERS}

The rest of the family (three children and the father) were also examined clinically, analytically, and radiologically (fig 4). Idiopathic osteolysis and nephropathy were discounted after the examinations. Strabismus and dorsal scoliosis with right convexity were found in the 15 year old sister. She also had feet cava (grade II) with claw toes and hallux valgus. Mild dorsal scoliosis, Sever's disease, and cava feet were found in the 11 year old brother. Another 16 year old boy had cava feet. 

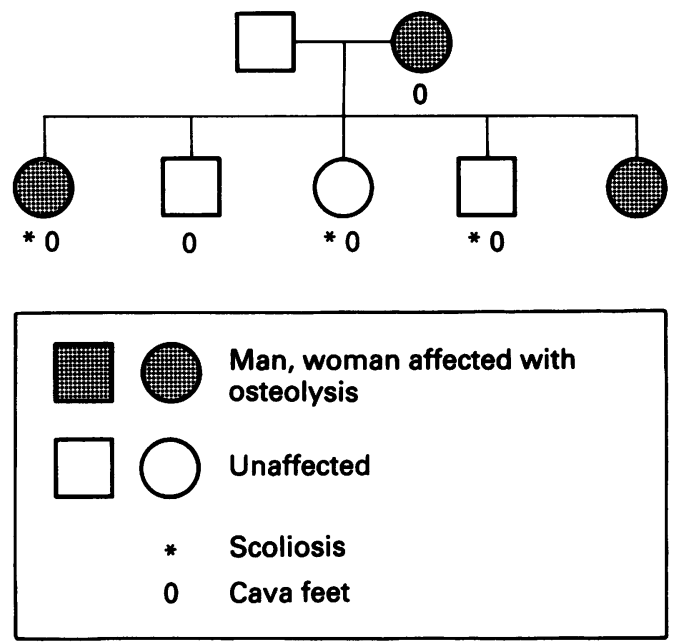

Figure 4 Family pedigree.

\section{Discussion}

In the family presented in this paper radiological findings typical of carpotarsal osteolysis are seen in patients 1 and 2 with distal osteolysis in the mother (patient 3). The family has primary idiopathic osteolysis with an autosomal dominant pattern of inheritance.

Thirteen families consisting of 40 subjects with the autosomal dominant form of carpotarsal osteolysis have been described. ${ }^{3}$ 6-20 The disease can be transmitted by either parent but there is a maternal predominance. The distribution between sexes is similar. The progression of the disease is characteristic. At about 4 years of age (range 9 months to 14 years) the patient begins to have pain and swelling in the hands and feet. These initial symptoms can be associated with a minor trauma, ${ }^{11} 1420$ a biopsy, or a slight illness. ${ }^{8}$ Over a period of a few years partial or complete resorption of the affected bones occurs. In most patients the bones of the carpus $(100 \%)$ and the tarsus $(60 \%)$ are affected and because of this Beals and Bird ${ }^{21}$ have called the disease carpotarsal osteolysis. A large number of patients, however, also have osteolysis of the metacarpals (40\%) and distal epiphysis of the radius, ulna, and humerus (40\%). The metatarsal, phalange, elbow, hip, knee, and sacroiliac joints are affected much less often. The changes are similar to those reported here. Radiological examination of patient No 1 showed that the proximal joints were not affected, though she had pain in one elbow.

The clinical and radiological pattern of patient 3 with osteolysis of the phalanges but not the carpal or tarsal joints should also be noted. It is possible that this family has a variant or combination of idiopathic osteolysis.

Carpotarsal osteolysis is habitually symmetric, though our second patient had asymmetric osteolysis, possibly because of the shorter time of disease progression.

Other clinical findings are cava feet, a triangular shaped face with a protruding forehead, micrognathia, exophthalmos, scoliosis, contractions similar to those in Dupuytren's contracture and camptodactyly. Several of these were present in this family.

From adolescence to the fourth decade of life deformities appear, such as a shortening of the affected areas, ulnar deviation, instability of the wrist, and complete dissolution of the affected bones which can be associated with extrusion of bone by sequestrum through the adjacent skin ${ }^{8}$ and on other occasions with fusion of the carpal bones. ${ }^{14}$ The disease tends to stabilise around the age of 35 , although recurrences have been reported. ${ }^{3}$

Idiopathic osteolysis as seen radiographically produces a slow and progressive resorption of bone affecting principally the carpal, tarsal, metacarpal, metatarsal, and elbow joints. Initially, erosions with well defined sclerotic edges and osteoporosis are observed, which eventually present fragmentation, sequestrum, and necrosis, and occasionally the complete disappearance of the affected bones. ${ }^{22}$ The ulnar and radial then draw nearer to the metacarpal joints, the edges of which present a sharpened appearance. This can also be observed in the phalanges. ${ }^{123}$ Osteolysis is seen in the larger joints but predominantly in the elbow. Hypoplasia of the cortex, thoracic scoliosis, and platybasia have been other occasional radiological findings. The age of the bone is usually normal. In some studies arthrographic findings have been normal ${ }^{20}$ and in the bone scan hypercaptation has been present in the areas of osteolysis. ${ }^{14} 21$

Apart from the characteristic radiological findings in this disease the biological studies are usually normal. In some patients high erythrocyte sedimentation rates have been seen and high levels of $C$ reactive protein $^{6812}$ and hydroxyproline in urine. ${ }^{12} 14$ HLA typing has been performed in one family ${ }^{14}$ but the results were not conclusive.

The tissues affected by idiopathic osteolysis generally show an increase in fibrous elements and in vascularity with little sign of inflammation. ${ }^{24-26}$ Bone formation is normal as indicated by the tetracycline uptake test. ${ }^{\text {" }}$ Biopsy samples taken from the affected joints show synovial and cartilaginous anomalies of little importance which are substituted by fibrocellular tissue.

Prognosis is generally acceptable in patients with the autosomal dominant form of the disease. Patients gradually lose strength in their hands and feet with articular instability. In some patients severe contractures of the knee, shoulders, and elbows occur with secondary osteoarthrosis of the weightbearing joints. One case has been reported of a patient who died of renal insufficiency. ${ }^{22}$

The treatment of idiopathic osteolysis is symptomatic using orthesic treatment of the affected joints, active muscular exercise, and analgesics and non-steroidal anti-inflammatory drugs in the active stages. Steroids do not prevent the evolution of the disease.$^{18}$ Operations have been unsuccessful in various patients owing to resorption of the grafted bones and instability of the arthrodesis. ${ }^{82027}$

The pathogenic mechanism of idiopathic osteolysis is unknown. A primary defect in the osteocartilaginous tissues has been suggested, or a secondary effect as a result of the primary proliferation of fibrous tissues. ${ }^{14}$ The occasional 
Differential diagnosis of osteolysis

Predominance of carpotarsal osteolysis
Idiopathic carpotarsal osteolysis
Autosomal dominant
Autosomal recessive
Sporadic
Winchester's syndrome
Francois' dermocorneal dystrophy
Other idiopathic multicentric osteolyses
Farber disease
Gorham's massive osteolysis
Idiopathic osteolyses in the adult
Multicentric reticulohistiocytosis
Predominance of osteolysis in the distal phalanges
Acro-osteolysis syndromes of Joseph and Shinz
Acro-osteolysis of Hadju-Cheney
Neurogenous acro-osteolysis
Neuroarthropathy in leprosy and diabetes
Vinyl chloride disease
Systemic progressive sclerosis
Raynaud's phenomenon
Dermatomyositis
Psoriatic arthritis
Hyperparathyroidism
Sarcoidosis
Miscellaneous
Mucolipoidosis type III
Chronic juvenile arthritis
Osteonecrosis
Post-traumatic osteolysis
Osteolysis secondary to gangrene, aneurism, or tumour
Thiemann's disease

finding of high levels of hydroxyproline in urine and alkaline phosphatase in serum ${ }^{612}$ can indicate progressive bone destruction or the presence of an underlying metabolic disease characterised by an increase of bone replacement. Other workers have proposed a hereditary immune mechanism similar to that of Goodpasture, ${ }^{3}$ although an autoimmune aetiology has been discounted. ${ }^{14} \mathrm{~A}$ pathogenic vascular mechanism supported by histological findings in the periarticular tissues and kidneys has been suggested. ${ }^{8}$

The differential diagnosis must be made from the group of diseases encompassing primary idiopathic osteolysis (table). ${ }^{23}{ }^{28-43}$ Carpotarsal osteolysis has two forms. Autosomal recessive carpotarsal osteolysis is associated with general osteoporosis, narrowing of the cortical and lengthening of the tubular bones, fusiform lengthening of the fingers and toes and contractions on flexion of the palms and on the soles of the feet and hyperpigmented lesions. ${ }^{44}$

Twenty seven cases have been described of the sporadic form of carpotarsal osteolysis. ${ }^{2} 45192224-2745-59$ The fundamental characteristic of this sporadic form is the presence of nephropathy. ${ }^{43}$ It habitually manifests with proteinuria between the ages of 12 months and 17 years, renal insufficiency develops and death occurs around 15-25 years of age. Chronic glomerulonephritis is usually seen in renal biopsy samples. ${ }^{24} 255057$

1 Resnick D, Niwayama G. Osteolysis and chondrolysis. In: Resnick D, Niwayama G, eds. Diagnosis of bone and joint disorders. Philadelphia: Saunders, 1988: 4140-70

2 Froelich Corret P. Ostéolyse du Carpe. Revue Medicale de Nancy 1937; 65: 696-9.

3 Tyler T, Rosenbaum H D. Idiopathic multicentric osteolysis. Am Y Roentgenol 1976; 126: 23-31.

4 Torg J S, Steel H H. Essential osteolysis with nephropathy. A review of the literature and case report of an unusual syndrome. F Bone foint Surg [Am] 1968; 50: 1629-38.

5 MacPherson $R$ I, Walker $R$ D, Kowall M H. Essential osteolysis with nephropathy. Foumal Canadian Association of Radiologists 1973; 24: 98-103.
6 Thieffry S, Sorrell-Dejerine J. Forme spéciale d'osteolyse essentielle héréditaire et familiale á stabilisation spontanée survenant dans l'enfance. Presse Med 1958; 66: 1858-61.

7 Omer G E, Mossman D L. Bone agenesis. A case involving the carpus and tarsus. $\mathcal{F}$ Bone foint Surg [Am] 1958; 40: 917-20.

8 Shurtleff D B, Sparkes R S, Cawson D K, Duntheroth W G, Mottet N K. Hereditary osteolysis with hypertension and nephropathy. FAMA 1964; 188: 363-8.

9 Coleman S S, Litton R J, Christensen W R. Familial dysostosis carpi. F Bone foint Surg [Am] 1965; 47: 850-6.

10 McManus M L, Ballard A. Carpal and tarsal agenesis with features of essential and hereditary osteolysis. $\mathcal{F}$ Bone foint Surg [Am] 1972; 54: 1099-104.

11 Gluck J, Miller J J 3rd. Familial osteolysis of the carpal and tarsal bones. F Pediatr 1972; 81: 506-10

12 Kohler E, Babbitt D, Huizenga B, Good T A. Hereditary osteolysis: a clinical, radiological and chemical study. Radiology 1973; 108: 99-105.

13 Erickson C M, Hirschberger M, Stickler G B. Carpal-tarsal osteolysis. If Pediatr 1978; 93: 779-82.

14 Whyte M P, Murphy W A, Kleerekoper M, Teitelbaum L, Avioli L V. Idiopathic multicentric osteolysis. Arthritis Rheum 1978; 21: 367-76.

15 Fryns J P, Pedersen J C, Hauglustaine D, et al. Carpal and tarsal osteolysis. Ann Genet 1980; 23: 123-5.

16 Fryns J P. Osteolysis éssentielle á debut carpien et tarsien. f Genet Hum 1982; 30: 423-8.

17 Lemaitre L, Remy J, Smith M, et al. Carpal and tarsal osteolysis. Pediatr Radiol 1983; 13: 219-26.

18 Addor M C, Pescia G, Egloff D, Queloz J. Osteólyse multicentrique héréditaire. $\mathcal{F}$ Genet Hum 1986; 34: 293-303.

19 Carnevale A, Canún S, Mendoza L, Del Castillo V. Idiopathic multicentric osteolysis with facial anomalies and nephropathy. Am $\mathcal{F}$ Med Genet 1987; 26: 877-86.

20 Krauss C M, Herman T E, Holmes L B. Unilateral carpal bone deformity in mother and son. A $m \mathcal{F}$ Med Genet 1987; 26: 557-63.

21 Beals R, Bird C B. Carpal and tarsal osteolysis. A case report and review of the literature. $\mathcal{F}$ Bone foint Surg [Am] 1975; 57: 681-6.

22 Amin P H, Evans A N W. Essential osteolysis of carpal and tarsal bones. Br F Radiol 1978; 51: 539-40.

23 Cazalis P. Acroosteolysis of the hand. Ann Radiol 1982; 25: 337-40.

24 Marie J, Salet J, Léveque B, Sauvegrain J. Syndrome ostéodystrophique de nature congenitale probable: realisant l'association d'une osteolyse essentielle progressive des os des extremités des membres et d'anomalies malformatives vertebráles et costales. Presse Med 1956; 44: 2173-6.

25 Bennett $W$ M, Houghton D C, Beals R C. Nephropathy of idiopathic multicentric osteolysis. Nephron 1980; 25: $134-8$.

26 Hardegger F, Simpson L A, Segmueller G. The syndrome of idiopathic osteolysis. Classification, review, and case report. F Bone Foint Surg [Br] 1985; 67: 89-93.

27 Thacker $\mathbf{C}$. Failure of arthrodesis of the wrist in "disappearing" bone disease. F Royal Coll Surg Edinb 1987; 32: 385-6.

28 Edeicken J. Bone dysplasias. In: Edeicken. Buenos Aires: Ed Med Panamericana, 1984: 1397-403.

29 Joseph R, Nezelof C, Gueraud L, Job J C. Acro-ostéolyse idiopathique familiale. Semin Hop Paris 1959; 35: 622-9.

30 Lamy M, Maroteaux P. Acro-ostéolyse dominante. Arch Fr Pediatr 1961; 18: 693-702.

31 Cheney W D. Acro-osteolysis. Am $\mathcal{f}$ Roentgenol 1965; 94: 595-607.

32 Winchester P, Grossman $H, \operatorname{Lim} W N$, et al. A new acid mucopolysaccharidosis with skeletal deformities simulating rheumatoid arthritis. Am $\mathcal{F}$ Roentgenol 1969; 106: 121-8

33 Hollister D W, Rimoin D L, Lachman R S, Cohen A H, Reed W S, Weston G W. The Winchester syndrome: a nonlysosomal connective tissue disease. $\mathcal{F}$ Pediatr 1974; 84: 701-9.

34 François J, Detrait C. Dystrophie dermochondrocornéenne familiale. Ann Pediatr 1950; 174: 145-74.

35 Bierman S M, Edgington T, Newcomer V D, et al. Farber's disease: a disorder of mucopolysaccharide metabolism with articular, respiratory, and neurologic manifestations. Arthritis Rheum 1966; 9: 620-30.

36 Gorham L W, Stout A P. Massive osteolysis (acute spontaneous absorption of bone, phantom bone, disappearing taneous absorption of bone, phantom bone, disappe
bone). $\mathcal{J}$ Bone foint Surg [Am] 1955; 37: 985-1004.

37 Renie W A, Pyeritz R E. Idiopathic multicentricosteolysis in a 78-year-old woman. Fohns Hopkins Medical foumal 1981; 148: $165-71$.

38 Tookman A G, Paice E W, White A G. Idiopathic multicentric osteolysis with acroosteolysis. A case report. $\mathcal{F}$ Bone foint Surg [Br] 1985; 67: 86-8.

39 Bortz A I, Vincent M. Lipoid dermato-arthritis and arthritis mutilans. Am f Med 1961; 30: 951-60.

40 Melhem R, Dorst J P, Scott C I, McKusick V A. Roentgen findings in mucolipidosis III (pseudo-Hurler polydystrophy). Radiology 1973; 106: 153-60.

41 Cassidy J T. Miscellaneous conditions associated with arthritis in children. Pediatr Clin North Am 1986; 33: 1033-52.

42 Sartoris D J, Resnick D. The radiographic differential diagnosis of juvenile chronic arthritis. Aust Paediatr $\mathcal{J} 1987$ 23: $273-5$.

43 Sybert V P, Motulsky A G. Renal involvement in hereditary multiple osteolysis. Lancet 1976; i: 52

44 Torg J S, DiGeorge A M, Kirkpatrick J A Jr, Martinez M. Hereditary multicentric osteolysis with recessive transmission: a new syndrome. 7 Pediatr 1969; 75; 243-52. 
45 Marie J, Levéque B, Lyon G, Bebe $M$, Watchi J M. Acroostéolyse essentielle compliquée d'insuffisance rénale d'evolution fatale. Presse Med 1963; 71: 249-52.

46 Neyroud $M$, Baumgartner J, Lenoir A, Un cas d'ostéolyse essentielle. Helv Paediatr Acta 1956; 11: 155-71.

47 Derot M, Rathery M, Rosselin G, Catellier C. Acro-ostéolyse du carpe, pied creux, scoliose et strabisme chez une jeune fille atteinte d'une insuffisance rénale. Bull Soc Med Hop Paris $1961 ; 77: 223-8$.

48 Normand I C, Dent C E, Smellie J M. Disappearing carpal bones. Proc $R$ Soc Med 1962; 55: 978-9.

49 Herrault A, Cohen-Sogal J, Duhamel A, DeGouyon F. Acroostéolyses idiopathiques de l'enfant. Ann Ped 1965; 12: 714-21.

50 Berthoux F, Robert J M, Zech P, Fries D, Traeger J. Acroostéolyse essentielle á début carpien et tarsien avec nephropathie. Arch Fr Pediatr 1971; 28: 615-30.

51 Counahan R, Simmons M J, Charlwood G J. Multifocal osteolysis with nephropathy. Arch Dis Child 1976; 51: osteolysis
52 De Smeet A. Acro-osteolysis occurring in a patient with idiopathic multicentric osteolysis. Skeletal Radiol 1980; 5 29-34.

53 Ludwig U, Karpk P M. A case of carpo-tarsal osteolysis. Handchinurgie 1980; 12: 97-100.

54 Gagnadoux M F, Bacri J L, Gluber M C, Broyer M. Acroosteolysis nephropathy report of a case: natural history and treatment by haemodialysis and transplantation. Int Pediatr Nephrol 1981; 2: 143-4.

55 Lameiras F M. Acroosteolysis. Handchir Mikrochir Plast Chir 1983; 15: 83-5.

56 De Stefano P, Pignatti C B, Bailo C. Radiological case of the month. Am F Dis Child 1985; 139: 739-94.

57 Tuncbilek E, Besin A, Bakkaloglu A, Turner E, Secmeer G Carpal-tarsal osteolysis. Pediatr Radiol 1985; 15: 255-8.

58 Hirooka $M$, Hirota $M$. Chronic nephropathy in idiopathic multicentric osteolysis. Int $\mathcal{J}$ Pediatr Nephrol 1985; 6 ; $145-50$.

59 Vichi G F, Falcini F, Pieratelli M, Jenuso R, Ceruso M. Case report. Skeletal Radiol 1986; 15: 665-71. 